\title{
PIBID Química na escola: reflexões sobre a formação docente na tripla articulação entre coordenação de área, supervisores e licenciandos
}

PIBID Chemistry at school: reflections on teacher training in the triple articulation between area coordination, supervisors and undergraduate students Lílian Souza Conceição Santos Rodrigo da Luz Gil Luciano Guedes dos Santos

Resumo. Este relato apresenta como objetivo principal discutir sobre o processo de formação docente dos participantes do PIBID, subprojeto Química, do Curso de Licenciatura em Química da UFRB. As ações realizadas durante o programa foram relatadas do ponto de vista dos supervisores e do coordenador de área. As múltiplas relações existentes entre a coordenação de área, a supervisão, os alunos bolsistas de iniciação à docência, os alunos do Ensino Médio e a unidade escolar são mostradas e discutidas. As intervenções realizadas, as reuniões específicas e gerais, as estratégias pedagógicas não-convencionais foram detalhadas pelos supervisores e pelo coordenador. Essas estratégias não-convencionais de ensino utilizando ludicidade ou jogos, por exemplo, motivaram e facilitaram a compreensão dos conteúdos de Química. A realização das reuniões e o planejamento das atividades foram importantes para a fluidez das ações do programa. A participação no PIBID é uma significativa oportunidade de constituição dos saberes docentes necessários à prática didático-pedagógica no contexto escolar. As atividades desenvolvidas evidenciaram a estreita relação que existe entre a Instituição de Ensino Superior e as Escolas de Educação Básica. Além disso, as ações que foram desenvolvidas promoveram significativas mudanças na realidade da escola pública no que concerne ao ensino de Química, visto que o ingresso de alunos nos cursos de Licenciatura em Química oriundos das escolas de Ensino Básico tem crescido nos últimos anos. A participação no PIBID tem motivado os alunos do curso de Licenciatura em Química a permanecerem na área de educação como futuros professores.

Palavras-chaves: PIBID. Ensino de Química. Formação Docente.

Abstract. This report presents as main objective to discuss the process of teacher training for PIBID participants, Chemical subproject, of the Chemistry Course at the UFRB. The actions carried during the program were reported from the point of view of the supervisors and the area coordinator. The multiple relationships that exist between area coordination, supervision, scholarship initiation students, High School students and the school unit are shown and discussed. The interventions carried out, the specific and general meetings, the non-conventional pedagogical strategies were detailed by the supervisors and the coordinator. These non-conventional teaching strategies using playfulness or games, for example, motivated and facilitated the understanding of the contents of Chemistry. The holding of meetings and the planning of the activities were important for the fluidity of the program's actions. Participation in PIBID is a significant opportunity to build the teacher knowledge necessary for didacticpedagogical practice in the school context. The activities developed showed the close relationship that exists between the Institution of Higher Education and the Schools of Basic Education. In addition, the actions that were developed promoted significant changes in the reality of the public school with regard to the teaching of Chemistry, 
since the enrollment of students in the Chemistry Degree courses from Basic Schools has grown in recent years. Participation in PIBID has motivated students in the Chemistry Degree course to remain in the area of education as future teachers.

Keywords: PIBID. Chemistry teaching. Teacher Training.

\section{Introdução}

O Programa Institucional de Bolsa de Iniciação à Docência (PIBID) da Universidade Federal do Recôncavo da Bahia (UFRB), Subprojeto de Química, vem desenvolvendo uma parceria com uma escola pública estadual em Amargosa/BA desde 2014. As atividades do programa são organizadas em encontros semanais na escola com supervisores e estudantes, além de encontros quinzenais ou mensais realizados na universidade junto a coordenação de área do PIBID Química. Durante esses encontros realizamos os planejamentos pedagógicos, bem como trazemos à discussão as necessidades e demandas latentes seja da escola ou universidade que precisam ser sanadas, a partir das quais pensamos e propomos ações, além de traçarmos os objetivos a serem alcançados pelos processos educativos desenvolvidos.

As atividades realizadas pelo PIBID na escola têm chamado a atenção do corpo de funcionários, professores e gestão que percebem a contribuição que o grupo tem dado à instituição. As atividades de formação têm contribuído para potencializar o processo de ensino e aprendizagem, trazendo inovações didático-pedagógicas que colaboram para tornar as aulas mais dinâmicas e interessantes para os estudantes do Ensino Médio.

No período de 2018 a 2020, o grupo de estudantes bolsistas e voluntários integrantes do PIBID puderam perceber a escola como um espaço social dinâmico e fluido que se constitui para além de seus muros, uma vez que se faz profundamente imbricada com o contexto sócio-político mais amplo onde está imersa. Trata-se de uma concepção de escola como campo de formação do futuro professor que está em construção e se constitui como profissional da educação a partir de uma sólida formação teórica e prática, cuja função se verifica na formação de sujeitos críticos capazes de participarem ativamente das decisões sociais, de pensar novas propostas e estratégias para contribuir 
com o ensino de Química na referida escola pública, da construção de uma relação professor-aluno de forma mais humana e afetuosa e de não apenas se adequarem ao mercado de trabalho.

Dessa forma, esse texto busca discutir sobre o processo de formação docente dos participantes do PIBID, refletindo sobre as experiências vivenciadas entre supervisores, licenciandos e a coordenação de área do programa na estreita relação entre escola e universidade.

Como aportes metodológicos essa pesquisa possui uma abordagem qualitativa, que de acordo com Minayo (2001) se preocupa com os sentidos que os sujeitos dão para a realidade num universo de significados que inclui suas experiências, vivências, percepções e valores. Trata-se ainda de uma pesquisa do tipo relato de experiência, que toma como objeto de análise os fatos vivenciados na prática de pesquisa sob um viés descritivo-interpretativo de maneira a possibilitar o compartilhamento de informações e a construção de conhecimentos. Considerando as atividades desenvolvidas de forma colaborativa pelos principais atores do PIBID na relação universidade-escola intencionamos a socialização de práticas didático-pedagógicas que possam contribuir para a melhoria contínua da formação de professores de Ciências/Química.

\section{O PIBID Química na escola}

Durante a atuação na escola, os licenciandos estiveram envolvidos na leitura de artigos da área de ensino de Ciências, bem como no aprofundamento teórico em temas contemporâneos que apresentam relação mais estreita com o ensino de Química. Tal fato permitiu que as intervenções realizadas fossem conduzidas pela teoria, potencializando o alcance dos objetivos previamente elaborados a partir de uma maior relação entre formação didático-pedagógica e implementação de estratégias e ações.

Pensando numa estrutura formativa que pudesse ter um caráter pedagógico, organizamos o PIBID em quatro grupos de formação: Grupo 01 Materiais Didáticos para o ensino de Ciências/Química I; Grupo 02 - Materiais Didáticos para o ensino de Ciências/Química II; Grupo 03 - Educação 
Ambiental e Educação CTS na Educação em Ciências; e Grupo 04 Agroecologia e Educação em Ciências. Esses grupos de formação foram criados observando os interesses dos licenciandos e considerando as linhas de pesquisa adotadas pelos supervisores e pelo coordenador de área do núcleo. Cada integrante do PIBID foi alocado em um dos grupos de maneira que todos passassem a desenvolver alguma atividade formativa supracitada. Os grupos 01 e 02 incorporaram duas propostas que vinham sendo desenvolvidas no PIBID relacionadas aos materiais didáticos Tabela Periódica e Bingo Eletrônico, respectivamente. As atividades dos demais grupos de formação foram iniciadas posteriormente e continuaram sendo desenvolvidas com os egressos do grupo, possibilitando ampliar o leque de experiências acadêmicas na vida do pibidiano. Acerca da Tabela Periódica, Galiza et al. comentaram:

A elaboração de uma Tabela Periódica Montável e de baixo custo (Figura 1, A e B) para ser utilizada durante as aulas de Química do Ensino Médio envolveu todos os integrantes do PIBID. Atrelada a melhoria da tabela, os pibidianos e supervisores refletiram coletivamente acerca das etapas da pesquisa que concerne à coleta e análise dos dados antes, durante e após as intervenções em sala de aula. Esse exercício reflexivo permitiu a ampliação da atividade para um público maior de alunos da escola. A proposta de intervenção foi confeccionar junto aos alunos uma Tabela Periódica montável, semelhante a um quebra cabeça, utilizando materiais de baixo custo para demostrar que a construção do conhecimento pode ser simples e viável, valendo-se de conceitos previamente abordados durante as aulas convencionais de Química na unidade letiva da escola, como por exemplo, localização do elemento químico, camada de valência, distribuição eletrônica (GALIZA et al., 2019, p. 855).

A intervenção foi realizada nas quatro turmas do $2^{\circ}$ ano integral e, posteriormente, em uma turma do $3^{\circ}$ ano noturno da escola (Figura 1, B e C). Com os resultados obtidos pudemos observar uma maior interação e problematização dos temas entre alunos e professores, bem como a aprendizagem de conceitos químicos por meio da construção de um ambiente mais lúdico. A intervenção contextualizada com os alunos do $3^{\circ}$ ano noturno possibilitou a apropriação dos conhecimentos científicos pelos alunos a partir de uma abordagem social dos conteúdos. 
Figura 1. Elaboração e implementação do Modelo Didático montável da Tabela Periódica.

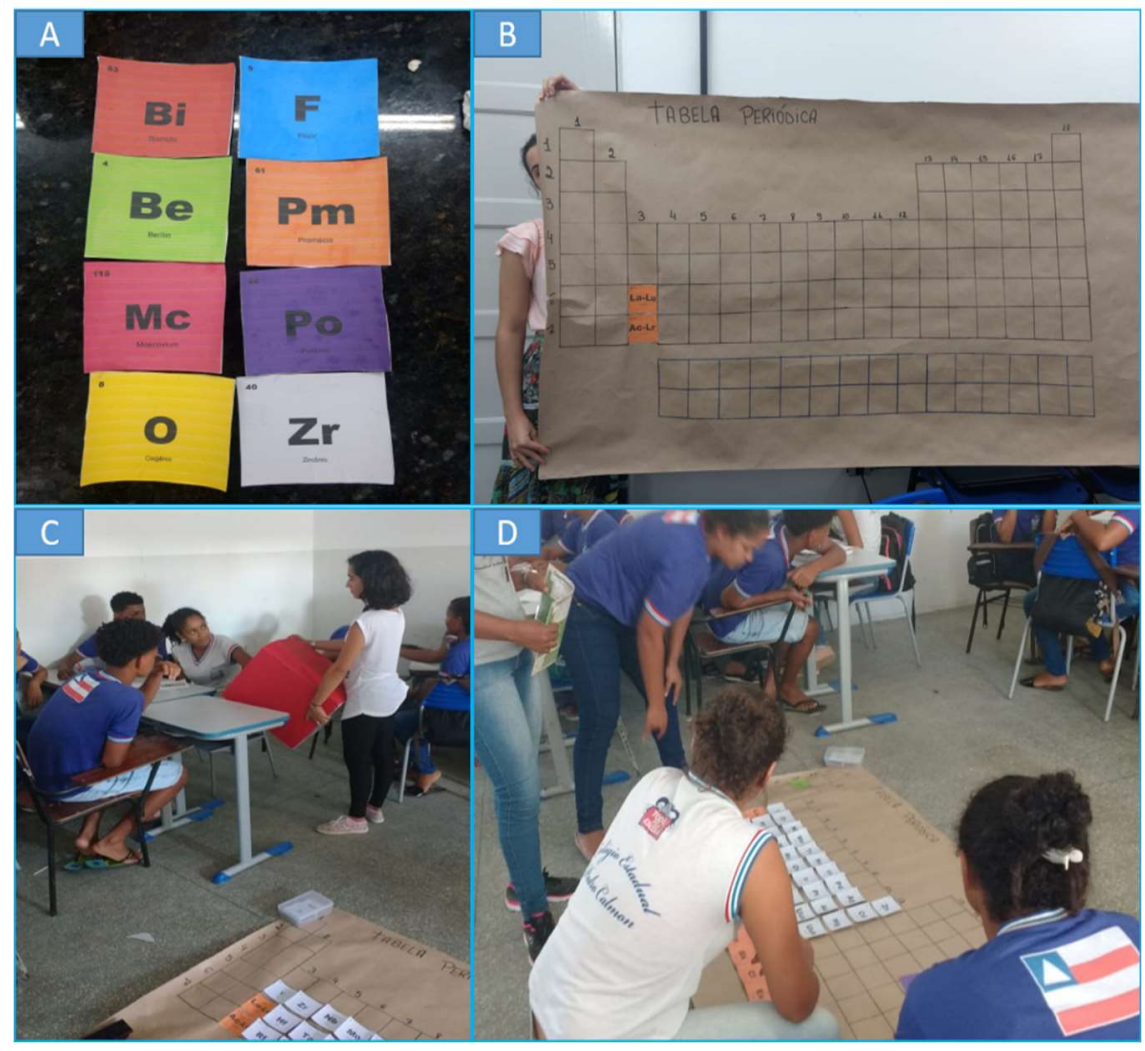

Fonte: Dados da pesquisa, 2019.

O Bingo Eletrônico ainda não foi efetivado em sala de aula, entretanto o modelo do jogo é uma proposta que poderá ser utilizada em qualquer prática pedagógica pelos pibidianos nos momentos subsequentes de seu curso ou nas aulas da própria escola. O jogo envolve o trabalho com o tema Ligações Químicas e objetiva a aprendizagem conceitual dos alunos sobre o assunto para que possam compreender os fenômenos envolvidos e intervir no mundo que fazem parte. De acordo com Maia et al.:

O jogo Bingo Eletrônico, construído com materiais de baixo custo, pode ser adaptado para trabalhar com vários conteúdos de Química presentes nos currículos da Educação Básica, sendo que neste trabalho, focamos na aprendizagem das Ligações Químicas. Na atividade são sorteados dois números a cada sequência de sorteio. A partir desses números, os alunos irão identificar os respectivos elementos químicos equivalentes utilizando seus números atômicos. Em seguida, deve-se informar o composto formado entre os elementos químicos em interação, levando em conta a regra do octeto e suas possíveis exceções (MAIA et al., 2019, p. 840). 
Trata-se de uma experiência inovadora no ensino de Ciências/Química que insere elementos didático-pedagógicos lúdicos capazes de promover 0 engajamento e a motivação dos estudantes em aprender os conteúdos disciplinares. Ressalta-se que esse jogo, por ser elaborado com materiais acessíveis e de baixo custo, pode ser adaptado para diferentes áreas e disciplinas, abrangendo distintos conteúdos e temáticas significativas presentes na realidade social e educativa.

Além da elaboração de materiais didáticos direcionados ao ensino de Ciências/Química, o grupo também esteve envolvido na organização das Olimpíadas Baiana de Química (OBAQ) na escola (Figura 02), exibindo protagonismo e autonomia para lidar com as demandas originadas durante 0 processo. A atividade exigiu dos pibidianos saberes e práticas necessárias ao trabalho em equipe e que envolvem valores de colaboração, solidariedade, coaprendizagem e coprodução.

Figura 2. Organização das Olimpíadas de Química na escola.

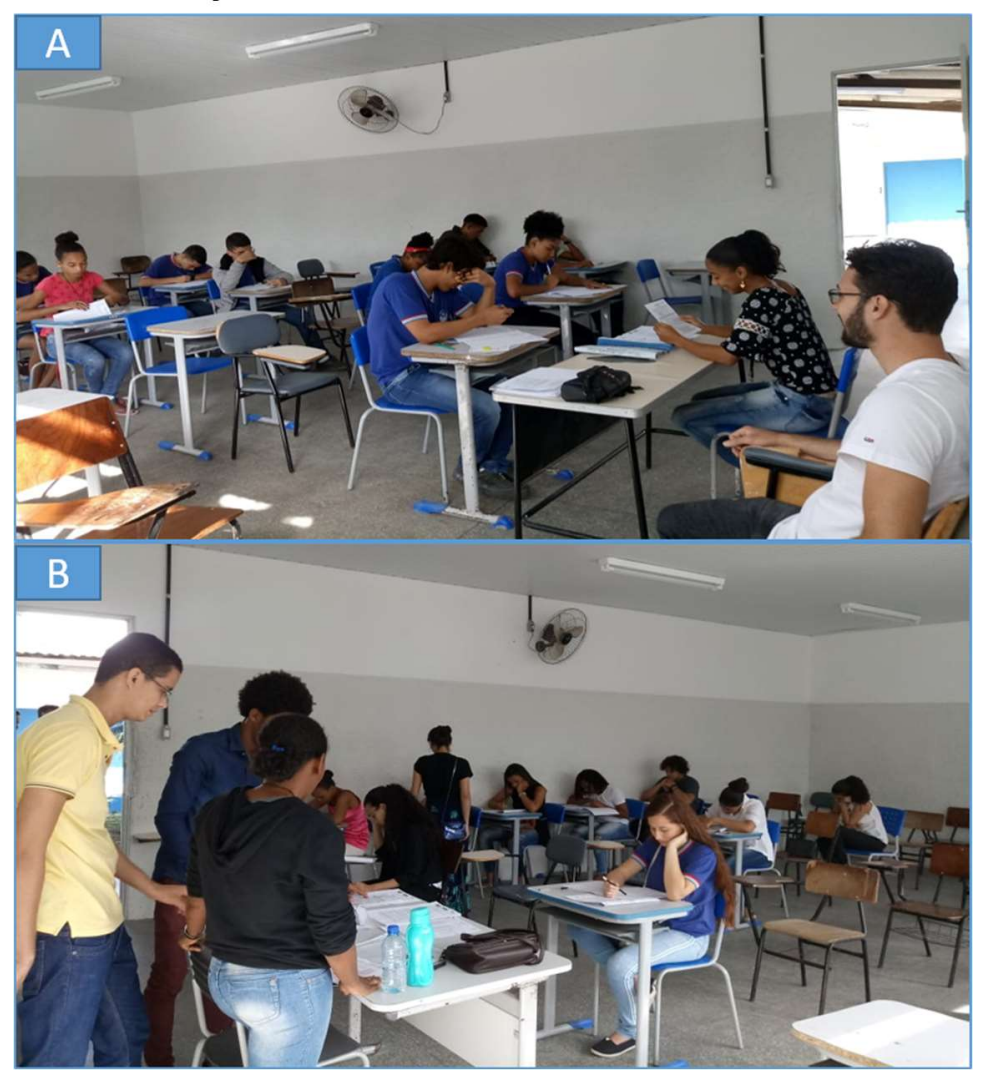

Fonte: Dados da pesquisa, 2019. 
Todas essas atividades pensadas e efetivadas pelo grupo são oriundas de um processo que não dissocia reflexão e ação, uma vez que os pibidianos refletem o tempo todo sobre as ações efetuadas na escola e universidade, seja durante as próprias intervenções realizadas, seja durante a escrita de artigos, participação em cursos presenciais/online, resumos, resenhas e relatos de experiência que culminam na participação em eventos da área, nas reuniões para avaliação das atividades realizadas e reflexões sobre os processos vividos. A esse respeito, o grupo participou ativamente da $V$ Reunião Anual de Ciência, Tecnologia, Inovação e Cultura (RECONCITEC) que ocorreu em 2019 na UFRB. Nesse evento foram publicados cinco artigos desenvolvidos em colaboração no PIBID e que sintetizam as principais atividades didáticopedagógicas do grupo desenvolvidas durante a vigência do projeto (Quadro 1).

Quadro 1. Trabalhos publicados nos anais do V RECONCITEC pelo PIBID Química da UFRB.

\begin{tabular}{|l|l|}
\hline Autores & Título \\
\hline Maia et al. (2019) & $\begin{array}{l}\text { Bingo Eletrônico: uma proposta lúdica para o } \\
\text { ensino de Química na Educação Básica }\end{array}$ \\
\hline Galiza et al. (2019) & $\begin{array}{l}\text { Tabela Periódica Montável: uma proposta } \\
\text { lúdica como estratégia motivadora para o } \\
\text { ensino de Química }\end{array}$ \\
\hline Jesus et al. (2019) & Conhecendo nosso campo de atuação \\
\hline Silva et al. (2019) & $\begin{array}{l}\text { O ensino de Química na concepção docente: } \\
\text { investigação dos integrantes do PIBID/ UFRB }\end{array}$ \\
\hline Santana et al. (2019) & $\begin{array}{l}\text { Percepçães de estudantes do Ensino Médio } \\
\text { sobre o ensino de Química: O PIBID vai à } \\
\text { escola }\end{array}$ \\
\hline
\end{tabular}

Fonte: Anais do V RECONCITEC UFRB.

Além da escrita e publicação de artigos, os pibidianos participaram de propostas formativas que foram desenvolvidas na escola, tal como, a Feira de Ciências, evento científico realizado anualmente no CEPC, que auxiliou os 
alunos nas etapas concernentes a atividade científica. Além disso, também colaboraram de forma significativa nas aulas de Química de turmas regulares da escola, pensando e realizando na aula prática de laboratório, exercícios de síntese e revisão, trabalhos em grupo, dentre outras proposições.

Essas atividades desenvolvidas pelo grupo contribuíram para fortalecer a relação universidade-escola por meio do tripé ensino, pesquisa e extensão, aliando a teoria à prática no sentido de contribuir para a formação dos estudantes da Educação Básica e do Ensino Superior.

\section{A supervisão como elo entre a escola-campo e a universidade: contribuições para a formação docente}

O PIBID Química do CEPC, no período de 2018 a 2020, contou com a atuação de dois supervisores responsáveis por vinte estudantes, sendo 16 bolsistas e 4 voluntários. As atividades dos supervisores foram realizadas de forma compartilhada, incluindo a coorientação dos estudantes, adequação dos horários destinados às reuniões do grupo e distribuição equitativa dos integrantes durante a organização e implementação das atividades na escola. Foi desenvolvido um trabalho coordenado com o intuito de buscar a superação das carências formativas relacionadas sobretudo a dimensão pedagógica que serviam de barreiras a compreensão crítica dos problemas presentes no espaço escolar pelos estudantes e, também, na busca pelo fortalecimento da relação entre teoria e prática.

No início do programa percebemos uma falta de entrosamento entre os participantes. É possível que a presença de alunos de semestres diferentes tenha causado essa falta de coletividade inicial. Esse fato repercutiu no processo coletivo de execução de tarefas, cumprimento dos prazos, retorno e avaliação dos resultados, ao passo que apontava para o processo de construção da identidade docente dos estudantes, fragilizado por questões sociais mais amplas presentes no contexto de formação. Uma identidade em

pleno processo de construção e que se faz intrinsecamente ligada com a reflexão e a ação na escola, enquanto lócus de atuação profissional dos 
licenciandos, guardando relação com suas histórias de vida, experiências pedagógicas, profissionais, culturais e ambientais.

A formação da identidade docente não é algo trivial, mas implica um movimento de idas e vindas, práticas e reflexões sobre o que significa ser professor e sobre qual professor queremos ser. Nessa perspectiva "a identidade não é um dado imutável, nem externo, que possa ser adquirido como uma vestimenta. É um processo de construção do sujeito historicamente situado" (PIMENTA, 2002, p. 76) que implica reflexões sobre sua constituição enquanto ser humano que estabelece interações político-pedagógicas com alunos.

recíprocos.

A partir das demandas identificadas na formação dos licenciandos, na escola e na universidade, foi desenvolvido um trabalho formativo pelos supervisores e o coordenador que objetivava a integração dos estudantes em torno de objetivos pedagógicos em comum com vistas a consideração e ao reconhecimento das diferenças, ao acolhimento mútuo e a colaboração participativa. Os estudantes necessitam de um olhar docente que contribua para sanar possíveis carências, atendendo-os em suas especificidades e ao mesmo tempo garantindo o avanço naquilo que eles possuem de potencial a ser explorado. Nesse sentido, torna-se necessário o desenvolvimento de um conjunto de saberes orientados para a formação do professor enquanto um profissional que precisa conhecer e atuar em seu local de trabalho por meio de conhecimentos curriculares, pedagógicos, disciplinares, experienciais e institucionais que orientam a prática educativa (TARDIF, 2002).

Observou-se o crescimento do grupo no que tange especialmente à prática científica e ao engajamento coletivo. Obviamente que esse crescimento não se deu de maneira igual para todos os integrantes do grupo. Entretanto, esse pôde ser notado, principalmente durante a avaliação do interesse do grupo na escrita de artigos para participação em eventos da área ou quando os licenciandos perceberam a necessidade de intervenção prática para amenizar ou mesmo solucionar algum problema por eles identificado na escola. 
O PIBID oportuniza o estreitamento dos laços entre a universidade e a escola e pode colaborar para o desenvolvimento de práticas fundamentadas numa educação transformadora que gerem mudanças na realidade. Pode contribuir também para a atuação docente dos supervisores, ao viabilizar a integração de saberes, muitos dos quais trazidos pelos licenciandos, acerca das inovações teórico-metodológicas para o ensino de Ciências construídas no campo acadêmico. Além disso, destacam-se contribuições para a prática profissional e pessoal relativas a saber trabalhar de forma coletiva e colaborativa, saber mediar conflitos e considerar a dimensão afetiva, dentre outros elementos. Ademais, a atuação no programa pode colaborar para a formação docente dos bolsistas e voluntários na direção de uma maior vinculação/transposição/significação entre aquilo que aprendem em seu curso e que efetivamente ensinam no chão da sala de aula, dependendo-se para isso de uma atuação colaborativa entre os principais atores do programa.

As necessidades presentes na escola, na universidade e no meio social mais amplo, demandam por supervisores que não apenas acompanhem as atividades desenvolvidas pelos licenciandos em sala de aula, mas que sejam profissionais sensíveis aos problemas emergentes no dia-a-dia do processo educativo, que saibam ouvir, opinar, participar e tomar decisões de maneira colaborativa e solidária. Os supervisores também contribuem com a formação dos licenciandos integrantes do PIBID ao Ihes apresentarem a dinâmica escolar e trazerem a sua experiência que serve como referência formativa e profissional para esses estudantes, num exercício constante de coformação (SILVA; BORGES; CORDEIRO, 2015).

\section{A coordenação de área como articulação da universidade e a escola- campo}

De acordo com as orientações da Coordenação de Aperfeiçoamento de Pessoal de Nível Superior (CAPES), a coordenação de área do PIBID tem como principais objetivos (a) planejar e acompanhar as atividades; (b) orientar e acompanhar a atuação do bolsista; (c) registrar a frequência nas atividades; (d) atuar em conjunto com os supervisores; (e) informar a coordenação 
institucional qualquer substituição, inclusão, desistência de bolsistas ou de supervisores do subprojeto que coordena; (f) participar de seminários regionais do PIBID e (g) quando solicitado, enviar ao coordenador institucional os documentos de acompanhamento dos bolsistas de iniciação à docência.

Inicialmente, o PIBID Química foi implantado com a sistematização de reuniões com todos os integrantes do programa (licenciandos, supervisores e coordenadores de área). A meta dessas reuniões foi acompanhar as ações de iniciação à docência em suas diversas dimensões. O grupo completo era formado por 30 (trinta) alunos da graduação (bolsistas e voluntários) divididos entre as 03 (três) escolas públicas estaduais vinculadas a UFRB.

Além do acompanhamento das atividades semanais in loco, a coordenação de área realizava reuniões mensais com todo o grupo para discutir as ações realizadas durante o referido período. Assim, os supervisores descreviam as atividades, os êxitos e os pontos negativos de cada ação. Da mesma maneira, os bolsistas e voluntários relatavam suas principais observações e aprendizagens naquele período. A iniciação à docência permitiu aos estudantes/participantes do PIBID a possibilidade de vivenciar na prática os conceitos teóricos, seja da Química "pura" como os relativos ao ensino de Química (específicos) que foram vistos na universidade. Assim, os estudantes puderam verificar o quanto a teoria se aproxima da prática e vice-versa quando se experimenta à docência em um ambiente real. A aprendizagem torna-se mais ampla quando se pensa no envolvimento com os diversos segmentos da instituição de ensino, tais como direção, docentes, discentes, administração, serviços gerais, etc.

Nas reuniões realizadas nas escolas, percebemos a necessidade de realizar projetos específicos e pontuais com a intenção de melhorar a aprendizagem e, principalmente, o interesse pela Química. No contexto dessas ações do PIBID na escola, aperfeiçoamos as ações no campo da contextualização, segundo as ideias de Wartha, Silva e Bejarano (2013), na tentativa de construir um ambiente de aprendizagem de Química por meio de atividades do cotidiano dos estudantes. Outra ação desenvolvida na escola permitiu o desenvolvimento de estratégias de ensino por meio de jogos 
didáticos. Na academia, os licenciandos bolsistas e voluntários no PIBID verificam essas possibilidades como ações que permitem o ensino dos conteúdos químicos, às vezes muito complexos, por meio da ludicidade. Segundo Cruz et al. (2020), a atividade lúdica aplicada ao Ensino Médio por meio de intervenções realizadas de forma dinâmica pode estimular o interesse dos alunos na aprendizagem de Química. A Tabela Periódica Montável e o Bingo Eletrônico foram propostas que corroboraram com essa estratégia de ensino lúdico. Assim, pudemos observar que a ideia de aplicação dessas estratégias permitiu aos estudantes verificar como os alunos do Ensino Médio reagiriam a um modelo de ensino diferente do convencional visto, muitas vezes, nos livros tradicionais e/ou conservadores de Química.

A partir dessas ações concretizadas nas escolas, verificamos que a inserção do PIBID tem mudado, mesmo que ainda de forma discreta, a realidade das escolas ao mobilizar atividades que valorizem as estratégias de ensino, a ludicidade, a utilização do espaço do laboratório, elaboração de feiras de Ciências etc. Além disso, a ações planejadas permitem em conjunto com a escola uma vivência cada vez mais intensa de intervenção com práticas educacionais mais contextualizadas. É possível que tenhamos um movimento de formação inicial articulado dos licenciandos de forma que possam mobilizar os saberes experienciais, disciplinares, curriculares e profissionais durante as atividades que foram realizadas nas ações planejadas.

A construção da prática docente é um exercício constante. Contudo, a formação inicial estabelecida na graduação mostra-se como um momento importante e significativo para a construção da identidade docente e as possíveis compreensões para o desenvolvimento profissional dos licenciados. Segundo Obara, Broietti e Passos (2017), em uma pesquisa realizada com participantes e egressos do PIBID para caracterizar a contribuição do programa para a formação dos professores, foi percebido na fala de todos os investigados o interesse, a motivação em discutir sobre o assunto e a presença de elementos que apontam para a construção da identidade docente.

$O$ papel do coordenador de área transcende aos estabelecidos pelos órgãos que fomentam o PIBID. A articulação entre a universidade e a escola 
perpassa pelos supervisores, licenciandos bolsistas e voluntários, pelos alunos, direção da unidade escolar, funcionários etc. Essa relação é muito complexa, pois fora desse círculo, o supervisor que atua, principalmente, na escola, tem a função de elo entre todos esses segmentos, a coordenação institucional e a CAPES.

Por isso, entende-se neste trabalho de coordenação uma complexidade que é vivenciada no cotidiano escolar e nas suas ações frente a UFRB de forma que possa contribuir com a constituição dos saberes necessários à docência em seus diversos aspectos, que considere a formação profissional, disciplinar, curricular e experiencial.

\section{Considerações Finais}

Nesse artigo discutimos sobre o processo de formação docente dos participantes do PIBID, a partir de reflexões sobre as experiências vivenciadas entre supervisores, licenciandos e a coordenação de área do programa na relação profícua que estabelecemos entre escola e universidade. Percebemos que essa relação é fundamental para a criação de laços entre esses espaços educativos, contribuindo para a superação da distância entre aquilo que se faz na Educação Básica e nas instituições de Educação Superior, em prol de um processo de ensino e aprendizagem em Ciências/Química cada vez mais crítico, coerente e contextualizado. Para alcançarmos esse intento é necessário o desenvolvimento de mais pesquisas que tomem como foco de investigação os principais atores do PIBID, como sujeitos que realizam processos educativos de maneira integrada e colaborativa, considerando as demandas socioculturais que atravessam a prática docente e que contribuem com a construção da identidade profissional desses professores em permanente formação.

O PIBID, enquanto programa formativo pode colaborar para o enfrentamento dos problemas cotidianos encontrados nas instituições escolares, bem como para preencher as demandas pedagógicas e socioemocionais presentes em seus integrantes, desde que supervisores, coordenadores e licenciandos trabalhem de maneira colaborativa com foco em 
processos formativos críticos mais humanos e, portanto, humanizadores. Além disso, pode proporcionar a vivência dos licenciandos com o ambiente escolar, com o trabalho docente, com as discussões que permearão a sua prática enquanto docente e a construção de propostas de intervenção para o Ensino de Química, buscando melhorar o aprendizado dos estudantes nesta disciplina que ainda se apresenta entre os componentes curriculares que os estudantes têm demonstrado mais dificuldades na escola.

\section{Agradecimentos}

Agradecemos a CAPES pelo apoio financeiro para a realização deste trabalho.

\section{Referências}

CRUZ, N. D. S. N.; BRITO, H. E. M.; SOUSA, F. J.; CARDOZO, R. M. D. A ludicidade no ensino de química: o uso da música como facilitador do processo de ensino-aprendizagem. Brazilian Journal of Development, v. 6, n. 7, p. 51179-51185, 2020.

GALIZA, L. S.; BRANDAO, M. N. S. A.; GRISE, M. V. T. R.; PEREIRA, R. R.; SILVA, S. L. S.; LUZ, R. Tabela Periódica Montável: uma proposta lúdica como estratégia motivadora para o ensino de Química. In: Anais da V Reunião Anual de Ciência, Tecnologia, Inovação e Cultura no Recôncavo da Bahia (RECONCITEC), 2019, Cruz das Almas/BA: UFRB, 2019. p. 855-855. Disponivel em: https://ufrb.edu.br/ppgci/anais-eventos-ppgci. Acesso em: 14 ago. 2020.

JESUS, D. D. S.; SANTOS, G. L. G.; SILVA, J. S; CARMO, J. S.; SANTOS, L. S. C. Conhecendo Nosso Campo de Atuação, In: Anais da V Reunião Anual de Ciência, Tecnologia, Inovação e Cultura no Recôncavo da Bahia (RECONCITEC), 2019, Cruz das Almas/BA: UFRB, 2019. p. 841. Disponível em: https://ufrb.edu.br/ppgci/anais-eventos-ppgci. Acesso em: 14 ago.2020.

MAIA, J. A.; SILVA, R. Q.; CARMO, J. S.; PEIXOTO, L. C.; SANTOS, L. S. C.; LUZ, R. Bingo Eletrônico: uma proposta lúdica para o ensino de Química na Educação Básica. In: Anais da V Reunião Anual de Ciência, Tecnologia, Inovação e Cultura no Recôncavo da Bahia (RECONCITEC), 2019, Cruz das Almas/BA: UFRB, 2019. p. 840-840. Disponível em: https://ufrb.edu.br/ppgci/anais-eventos-ppgci. Acesso em: 14 ago. 2020.

MINAYO, M. C. S. (Org.). Pesquisa Social: Teoria, método e criatividade. 18 ed. Petrópolis: Vozes, 2001. 
OBARA, C. E; BROIETTI, F. C. D.; PASSOS, M. M. Contribuições do PIBID para a construção da identidade docente do professor de Química. Ciência \& Educação (Bauru), v. 23, n. 4, p. 979-994, 2017.

PIMENTA, S. G. (Org.). Saberes Pedagógicos e Atividades Docentes. 3. ed. São Paulo: Cortez, 2002.

SANTANA, L. P. S.; PEIXOTO, L. C.; PEREIRA, R. R.; SILVA, R. Q.; SANTOS,

G. L. G.; SANTOS, L. S. Percepções de estudantes do ensino médio sobre o Ensino de Química: o PIBID vai à escola. In: Anais da V Reunião Anual de Ciência, Tecnologia, Inovação e Cultura no Recôncavo da Bahia (RECONCITEC), 2019, Cruz das Almas/BA: UFRB, 2019. p. 852. Disponível em: https://ufrb.edu.br/ppgci/anais-eventos-ppgci. Acesso em: 14 ago. 2020.

SILVA, M. R. S; MAIA, J. A.; BRANDÃO, M. N. S. A.; SILVA, S. L. S.; SANTOS, L. S. C. SANTOS, G. L. G. O Ensino de Química na concepção docente: investigação dos integrantes do PIBID/ UFRB. In: Anais da V Reunião Anual de Ciência, Tecnologia, Inovação e Cultura no Recôncavo da Bahia (RECONCITEC), 2019, Cruz das Almas/BA: UFRB, 2019. p. 851. Disponível em: https://ufrb.edu.br/ppgci/anais-eventos-ppgci. Acesso em: 14 ago. 2020.

SILVA, S. P.; BORGES, C. T.; CORDEIRO, J. F. O professor supervisor do PIBID: considerações sobre a prática e contribuições para a formação de novos docentes. In: FARIAS, I. M. S.; LIMA M. L. CAVALCANTE, M. M. D.; SALES, J. A. M. (Orgs.). Livro 2: Didática e Prática de Ensino na relação com a Formação de Professores. 1 ed. Fortaleza: EdUECE, 2015.

TARDIF, M. Saberes docentes e formação profissional. 2. ed. Petrópolis: Vozes, 2002.

WARTHA, E. J.; SILVA, E. L.; BEJARANO, N. R. R. Cotidiano e contextualização no ensino de química. Química Nova na Escola, v. 35, n. 2, p. 84-91, 2013.

\section{Sobre os autores}

\section{Lílian Souza Conceição Santos}

lilianscon@hotmail.com

Mestre em Educação do Campo (2020) e Especialista em Educação no Campo e Desenvolvimento Territorial do Semiárido Brasileiro pela Universidade Federal do Recôncavo da Bahia (2014). Licenciada em Biologia pela Universidade Federal da Bahia (2007). Atua como professora de Biologia da Rede Estadual de Ensino da Bahia.

\section{Rodrigo da Luz Silva}

rodrigoluz_saj@live.com

Licenciado em Biologia pela Universidade Federal do Recôncavo da Bahia UFRB (2012-2016), mestre em Educação em Ciências pela Universidade Estadual de Santa Cruz - UESC (2017-2019) e doutorando em Educação pela 
Universidade Federal da Bahia - UFBA (2019). Nessa universidade participa do grupo de Pesquisa Interfaces: Cultura, Ciência e Ambiente na Educação Crítica ligado ao grupo ENCIMA (Ensino de Ciências e Matemática). Desde 2019 atua como professor de Ciências/Biologia da Secretaria de Educação do Estado da Bahia (SEEBA) no município de Amargosa. Sócio da Associação Brasileira de Pesquisa em Educação em Ciências (ABRAPEC) e desenvolve pesquisas relacionadas à Perspectiva Freireana, Educação em Ciências, Educação Ambiental e Educação CTS/CTSA.

\section{Gil Luciano Guedes dos Santos}

gilluciano@ufrb.edu.br

Licenciado em Ciências (habilitação em Química) pela Universidade Estadual do Sudoeste da Bahia-UESB, Especialista em Educação Inclusiva pela Universidade Castelo Branco/RJ, Mestre em Química Analítica pela Universidade Estadual do Sudoeste da Bahia-UESB e Doutor em Química Analítica pela Universidade Federal da Bahia-UFBA. Atualmente é professor Adjunto da Universidade Federal do Recôncavo da Bahia-UFRB e desenvolve projetos de pesquisa e extensão nas áreas de Química Analítica, Química Ambiental e Ensino de Química. 